\title{
Horizontes latino-americanos do lazer/ Horizontes latinoamericanos del ocio Christianne L. Gomes y Rodrigo Elizalde
}

\author{
Editorial Universidade Federal de Minas Gerais (UFMG), \\ Belo Horizonte, Brasil, 2012, 343 págs.
}

\section{Marcina Amália Nunes Moreira}

Universidade Federal de Minas Gerais, Belo Horizonte, Brasil.

Email: marcinanunes@hotmail.com

La co-autora del libro es Post-doctora en Ciencias Sociales por la Universidad Nacional de Cuyo/Argentina, Doctora en Educación, Magister en Ciencias del Deporte y Especialista en Lazer (Ocio) por la Universidad Federal de Minas Gerais de Brasil (UFMG). El co-autor es Post-doctorando en Geografía Humana en la UFMG, Doctor y Magister en Educación con mención en Aprendizaje Transformacional por la Universidad Bolivariana de Chile (UB), Especialista en Educación Ambiental, Globalización y Desarrollo Sustentable (UNED/España), Psicólogo y licenciado en psicología (UB). Ambos son líderes del Grupo de Pesquisa OTIUM - Lazer, Brasil \& América Latina.

El libro "Horizontes latino-americanos do lazer / Horizontes latinoamericanos del ocio" es una obra bilingüe que permite una lectura fluida, profunda y comprometida con la comprensión del contexto en el cual está presente la temática del ocio en América Latina, buscando colaborar con los diálogos y debates ya iniciados en la región en este campo de estudios.

En este sentido, esta obra amplía y profundiza las formas de comprender al ocio, al ser entendido este como un derecho social y una necesidad humana, siendo a su vez una dimensión de la cultura, con potencial contrahegemónico y transformacional. De esta forma, las hipótesis y perspectivas trabajadas en los cinco capítulos del libro son abordadas de manera singular e innovadora por los dos autores, amparados por una formación académica interdisciplinar que expresa una visión crítica y problematizadora del contexto actual en que se envuelven las discusiones sobre una nueva forma de conceptualizar y contextualizar los estudios del ocio y la recreación en América Latina.

El primer capítulo es minuciosamente construido en torno a un ensayo sobre lo que es un concepto desde el punto de vista epistemológico, esbozando con cautela la relación que se establece entre el mundo social y el conocimiento sobre este, lo que ayuda a ampliar el entendimiento del 
lector acerca de la realidad. La ampliación de ese horizonte se funde a la contextualización de la propia expresión América Latina, que es tan utilizada pero al mismo tiempo tan poco comprendida, incluso en los textos académicos. De esta forma la preocupación central del primer capítulo es buscar conocimientos que permitan comprender el proceso de construcción conceptual y contextual de América Latina. Algunas preguntas claves son las siguientes: ¿Qué significa la expresión América Latina? ¿Cuándo, dónde y por qué fue elaborada? En este sentido, los estudios que componen el primer Capítulo de este libro resaltaron la urgente necesidad de comprender las parcialidades y limitaciones de la expresión América Latina buscando generar un aporte para su resignificación. Así se busca comprender el origen del término América Latina, buscando abrir un análisis de las consecuencias histórico-políticas de la adopción de este nombre. Paralelamente, este capítulo abre el debate sobre el pensamiento crítico y su construcción en Latinoamérica, destacando la necesidad de ampliar la discusión sobre la importancia de reconocer la diversidad que esta región presenta, al ser un territorio humano cargada de contrastes, polisemias, contradicciones, injusticias, desafíos pendientes y potencialidades.

El segundo capítulo propone una reflexión sobre los entendimientos de recreación y de ocio que predominan en el contexto latinoamericano. Se destacan las imprecisiones e indefiniciones conceptuales sobre ocio (“lazer”), recreación y tiempo libre, como una fragilidad de los estudios producidos sobre la temática en América Latina. Muchas veces estos términos son utilizados indistintamente, generando contradicciones y problemas de comprensión. La imprecisión y la confusión conceptual comprometen el avance de conocimientos sobre el tema en la región -que, tradicionalmente, enfatiza el concepto de recreación en menoscabo del concepto de ocio. ¿Por qué acontece esto? ¿Cuáles son los orígenes de los conocimientos producidos sobre la recreación, y de qué manera fueron difundidos en América Latina? En lo que se refiere al ocio, ¿Los saberes y teorías inicialmente elaborados sobre el tema son adecuados a nuestra región? Este capítulo ingresa en esas y otras cuestiones, indicando la necesidad de resignificar los saberes teórico-conceptuales sobre el ocio en América Latina desde una perspectiva contrahegemónica.

Siguiendo esta perspectiva, el libro postula que el ocio es una práctica social compleja que puede ser concebida como una necesidad humana y como una dimensión de la cultura caracterizada por la vivencia lúdica de manifestaciones culturales en el tiempo/espacio social. Esta comprensión fundamenta las reflexiones, análisis e interpretaciones de los autores, al entender que, como ellos indican, "el ocio es un fenómeno dialéctico que dialoga con el contexto y, por eso, es vulnerable y presenta ambigüedades y contradicciones. Así, el ocio puede tanto expresar formas de reforzar las inequidades, injusticias, alienaciones y opresiones sociales, como, por el contrario, representar una posibilidad de libertad y dignificación de la condición humana. Esta consideración resalta la necesidad de valorizar el potencial transformacional y crítico del ocio” (p.299). 
El tercer capítulo, desde una visión histórica, los autores cuestionan que al retroceder en el tiempo para estudiar el ocio, en la mayoría de los casos, se toma como punto de partida a las sociedades greco-romanas o a las modernas sociedades urbano-industriales europeas, lo que lleva a los autores a preguntar: ¿Qué otras relecturas sobre el ocio en América Latina se pueden hacer? ¿Las reflexiones sobre el ocio en América Latina deben considerar apenas las sociedades greco-romanas o urbano-industriales? ¿Cuáles son las implicaciones históricas, culturales, sociales, económicas y (geo) políticas de este tipo de abordaje en las distintas realidades latinoamericanas? En este sentido, al anunciar otras perspectivas de análisis, este capítulo procura contribuir con esta discusión.

Ampliando este foco de análisis, el libro presenta elementos que contextualizan al ocio y a la recreación en las realidades latinoamericanas, buscando superar la visión eurocéntrica, colonial y universal que prevalece en los estudios sobre la temática y en las ciencias humanas en general. Si, por un lado, la adopción de lecturas "importadas" de Europa es asumida como la principal fuente de conocimiento válido y legítimo, por otro, tales mecanismos limitan la capacidad de que las personas y los colectivos humanos consigan generar visiones propias sobre sí mismo, su sociedad y el mundo. En esta misma línea, el libro propone como horizonte de discusión la creación de conocimientos propios para y desde América Latina, posibilitando así el surgimiento de saberes coherentes y coincidentes con las prácticas de ocio existentes en esos contextos específicos, y al mismo tiempo, encontrando así pistas en la construcción de alternativas para la transformación social.

Ya en el cuarto capítulo, se destaca el que muchas veces cuando se trata sobre la temática del ocio este es abordado junto al trabajo, pues, son evidentes los vínculos sociales e históricamente constituidos entre estos dos fenómenos. Como el ocio no es una fracción aislada y está en íntima relación con los demás campos de la vida en sociedad, se vuelve clara la importancia de profundizar conocimientos sobre la problemática del trabajo en América Latina y sobre sus desafíos actuales. En coherencia con lo recién indicado en este capítulo se levantan las siguientes preguntas fundamentales: ¿La reducción de la jornada de trabajo significa una progresiva ampliación del tiempo libre, en especial en las sociedades latinoamericanas? ¿Qué papel asume el ocio en este proceso de reconfiguración del trabajo verificado en los días actuales? Es notoria la importancia de repensar críticamente estos y otros aspectos, pues, los problemas sociales, políticos y económicos que marcan la región latinoamericana necesitan ser enfrentados de modo urgente en vez de ser simplemente disfrazados o amenizados por programas recreativos no siempre comprometidos con una educación crítica y problematizadora.

De esta manera, es importante preguntar, como se hace en este libro: ¿cuál es el costo social y ecológico de este modelo capitalista de crecimiento, progreso y desarrollo, especialmente para las sociedades latinoamericanas? ¿De qué manera la educación favorece el mantenimiento de 
este modelo? ¿Qué tipo de educación posibilitará la transformación de esta realidad social, tornándola más solidaria y sustentable? ¿Cómo el ocio podría contribuir con estos desafíos desde América Latina? Estas preguntas, formuladas por los autores, indican la importancia de estimular el pensamiento crítico por medio de una educación comprometida con el ocio, que ayude a caminar hacia sociedades sustentables, que valoren una ética transcultural e intercultural. En términos generales, este es el tema abordado en el quinto y último capítulo.

Siendo así, este libro levanta muchos desafíos para este campo de estudios tales como la profundización del concepto de ocio transformacional en una perspectiva contra-hegemónica, así como la sistematización de estas herramientas en la vida cotidiana. Otro importante desafío propuesto a partir de la lectura de esta obra es la realización de futuras investigaciones sobre el ocio y la recreación en los diferentes contextos latinoamericanos, para evitar abordajes universalistas, que representan y son propios de otras realidades y no necesariamente acordes con las necesidades, problemáticas y potencialidades latinoamericanas. Todos estos desafíos generarán la posibilidad de emprender nuevas lecturas y comprensiones de nuestras propias historias frente a las investigaciones y estudios para y por un ocio transformacional que contribuya con la construcción de una Latinoamérica más humana.

Aunque algunas personas puedan pensar que investigar la temática del ocio en América Latina significa una moda pasajera, para los autores representa un ejercicio muy complejo, desafiador y necesario de profundizaciones comprometidas con el despertar de consciencias. Como las investigaciones y los estudios sobre la recreación y sobre el ocio en la región latinoamericana aun carecen de profundizaciones, muchas de las ideas desarrolladas en este libro se encuentran en elaboración, evidenciando lo temporal y el dinamismo del proceso de construcción del conocimiento. Por eso este libro sin duda es un aporte para emprender nuevos diálogos, reflexiones y perfeccionamientos sobre un tema tan relevante como el ocio en América Latina del siglo XXI.

Además este libro se encuentra disponible también en versión digital en: http://grupootium.files.wordpress.com/2012/06/horizontes_latino_ americanos_lazer_junho_20123.pdf 